\title{
Lentivirus-mediated RNA interference of E2F-1 suppresses Tca8113 cell proliferation
}

\author{
HUA YUAN ${ }^{*}$, FEI JIANG ${ }^{*}$, RUIXIA WANG, MING SHEN and NING CHEN \\ Institute of Dental Research, Nanjing Medical University, Nanjing, Jiangsu 210029, P.R. China
}

Received July 17, 2011; Accepted October 24, 2011

DOI: $10.3892 / \mathrm{mmr} .2011 .668$

\begin{abstract}
In most types of human cancer, inactivation of $\mathrm{pRb} /$ E2F complexes occurs, and released E2Fs initiate transcription of genes required for cell cycle progression. Evidence reveals that phosphorylated pRb deregulates E2F-1, and the levels of E2F-1 expression can accurately predict prognosis of oral squamous cell carcinoma (OSCC). Paradoxically, numerous reports indicate that E2F-1 is also capable of inducing apoptosis under certain cellular circumstances. In the present study, lentivirus-mediated shRNA was used to downregulate endogenous E2F-1 expression in order to study the function of E2F-1 in the $\mathrm{pRb} / \mathrm{E} 2 \mathrm{~F}-1$ pathway in the OSCC cell line Tca8113, and to investigate the alteration of Tca8113 cells in proliferation and apoptosis. The data from real-time quantitative RT-PCR and Western blot analysis showed that E2F-1-shRNA led to the inhibition of endogenous E2F-1 mRNA and protein expression, and E2F-1 may be associated with proliferation and apoptosis pathways. Growth kinetics data showed that Tca8113-E2F-1shRNA cells presented more active proliferation properties than Tca8113-NC cells, and flow cytometry data demonstrated that the percentages of cells in the G1 phase, G2 phase and undergoing apoptosis differed between groups. In conclusion, silencing of E2F-1 inhibits proliferation and induces apoptosis. E2F-1 may also be involved in multi-level regulation networks; therefore, its role in OSCC requires further clarification.
\end{abstract}

\section{Introduction}

Oral squamous cell carcinoma (OSCC) is the most common malignant tumor in the oral cavity, comprising more than $80 \%$ of cases of oral cancer (1). Although diagnostic and surgical techniques for treatment of OSCC have advanced in recent years, post-surgery survival rates have not improved. The overall 5-year survival rate of patients with OSCC has not

Correspondence to: Dr Ning Chen, Institute of Dental Research, Nanjing Medical University, 140 Hanzhong Road, Nanjing, Jiangsu 210029, P.R. China

E-mail: ningchen09@gmail.com

*Contributed equally

Key words: E2F-1, Tca8113 cells, cell cycle, proliferation, apoptosis significantly increased, and overall and disease-free survival rates remain at approximately 50\% (2).

One characteristic of all cancers is the ability to proliferate beyond the normal limits and constraints. To do this, the cell must acquire new properties, such as being able to deregulate cell proliferation and suppress cell death $(3,4)$. It is possible that multi-level regulation networks lead to the new properties of the mutated cells in their cell cycle. A nuclear protein called E2F-1 plays a key role in cell cycle control in most human cancers (4).

E2F-1 belongs to the E2F family that includes 8 genes (E2F-1 to E2F-8) to encode 9 distinct proteins in mammalian cells. E2F-1 is a cellular component that is required for the early region transforming protein $(\mathrm{E} 1 \mathrm{~A})$ of adenovirus to mediate transcriptional activation of the viral E2 promoter (5). Several other E2F family members have now been isolated, either through homology to E2F-1 or through binding to Rb-related proteins. In G0 and early G1 phases, the vast majority of E2F proteins are in complexes with $\mathrm{Rb}$ and related proteins (6), that inhibit the transcriptional activation capacity of E2F factors and, in certain cases, convert E2F factors to repressors of transcription. pRB can be phosphorylated and dissociates from E2F by upstream regulators in this pathway, such as p16 silencing, amplification of cyclin D1 or cdk4 (7), then activated E2Fs result in activation of E2F-responsive genes (e.g. those involved in DNA synthesis, cell cycle control, pocket protein expression, etc.)

E2F-1 regulates cell cycle progression through checkpoints in the cell cycle and plays a dual role in cancer development with the capacity to act both as a tumor suppressor and as an oncogene (8). As an oncogene, E2F-1 induces many genes, such as $\mathrm{Cdc} 2, \mathrm{Cdc} 25$, cyclin $\mathrm{E}$, which are regulated in a cell-specific manner and have E2F-binding sites as their promoters to express directly in quiescent cells to enter into DNA synthesis (9-11). As a suppressor gene, E2F1 also has the capacity to induce apoptosis, partly through induction of and cooperation with the p53-dependent pathway or p53-independent pathway (12). Overexpression of E2F-1 is detected in head and neck cell carcinoma and is associated with increased disease-free and overall survival (13).

Overexpression of E2F-1 is associated with increased disease-free survival in OSCC (14), however, the pathways involving E2F-1 are both multiple and interactive, and although numerous recent advances have elucidated these processes, many questions remain. Our previous research demonstrated 
a significant impact of E2F-1 overexpression on cell cycle progression and proliferation in an in vitro cell model of OSCC (15). The aim of the present study was to clarify the effects of E2F-1 knockdown on biological characteristics of OSCC in vitro. In particular, we were interested in E2F-1 as a target for the development of therapeutic methods in the treatment of this disease.

\section{Materials and methods}

Cell culture. Tca8113 cells were cultured in Dulbecco's modified Eagle's medium (DMEM) (Invitrogen, Gaithersburg, MD, USA) with $10 \% \mathrm{FBS}$, penicillin $(100 \mathrm{U} / \mathrm{ml})$, and streptomycin $(100 \mu \mathrm{g} / \mathrm{ml})(1 \%$ Pen/Strep). The cells were cultured in an incubator at $5 \% \mathrm{CO}_{2}$ and at $37^{\circ} \mathrm{C}$, with the replacement of medium every 3 days.

Constructs and production of lentivirus. The lentiviral vectors expressing short hairpin RNA (shRNA) were successfully constructed, as previously described. The effectively selected E2F-1 shRNA and negative control oligonucleotide (NC) sequences were designed according to the Sigma-Aldrich website (http://www.sigmaaldrich.com/sigma-aldrich/ areas-of-interest/life-science/functional-genomics-and-rnai/ shrna/productoverview.html) as follows: E2F-1-shRNA, sense: 5-CAGGATGGATATGAGATGGGACTCGAGTCC CATCTCATATCCATCCTG-3'; Negative control shRNA, sense: 5'- CCTAAGGTTAAGTCGCCCTCGCTCGAGCGAG GGCGACTTAACCTTAGG-3'. All of the above sequences were inserted into the AgeI and EcoRI enzyme sites of pLKO.1TRC cloning vector, which contains the U6 RNAi cassette. Following recombination reaction, using pCMV-dR8 and pVSVG vectors, lentiviral vector DNAs and packaging vectors were transfected into $293 \mathrm{~T}$ cells. Supernatants containing lentiviruses were harvested $48 \mathrm{~h}$ later, following transfection and purification using ultracentrifugation.

Infection of lentivirus. OSCC cells (Tca8113) were transduced with the above two types of lentivirus particles. The transduced Tca8113 cells were then selected by puromycin ( $2 \mu \mathrm{g} / \mathrm{ml})$, and puromycin-resistant colonies were then picked, expanded and analyzed separately. Tca8113 cells transduced with lentivirus-mediated shRNA targeting E2F-1 were named Tca8113-E2F-1-shRNA cells. Tca8113 cells transduced with lentivirus-mediated shRNA (NC) were named Tca8113-NC cells.

Reverse transcriptase-polymerase chain reaction (RT-PCR) analysis of E2F-1 mRNA expression. The cells (stably transfected) were harvested after selection by puromycin. Total RNA was extracted from cells using the RNeasy kit (Qiagen Inc., Valencia, CA, USA). The reverse transcription reaction was performed using high-capacity cDNA synthesis kit (Applied Takara Bio Inc., Madison, WI, USA). The products of PCR were checked by agarose gel electrophoresis and the abundance of each mRNA was detected and normalized to that of $\beta$-actin mRNA.

Real-time quantitative polymerase chain reaction (real-time PCR) analysis. Real-time PCR was performed using SsoFast ${ }^{\mathrm{TM}}$
EvaGreen ${ }^{\circledR}$ Supermix with ROX kit (Bio-Rad, Hercules, CA, USA) and the ABI 7300 real-time PCR system. Primers used in this experiment were as follows: E2 promoter-binding factor-1 (E2F-1), 5'-ACCCTGCAGAGCAGATGGTT-3' (forward) and 5'-TTTGCTCTTAAGGGAGATCTGAA-3' (reverse); rentinoblastoma protein (pRb), 5'-TTCAGCAG AAACTGGCAGAAATG-3' (forward) and 5'-CAGTGTCC ACCAAGGTCCTGAG-3' (reverse); cyclin E, 5'-TTTGC AGGATCCAGATGAAGA-3' (forward) and 5'-CACAGA CTGCATTATTGTCCCAAG-3' (reverse); p14, 5'-GGCACC AGAGGCAGTAACCA-3' (forward) and 5'-GGACCTTCG GTGACTGATGATCTAA-3' (reverse); p53, 5'-AGAGCTG AATGAGGCCTTGGAA-3' (forward) and 5'-GAGTCAGGC CCTTCTGTCTTGAAC-3' (reverse); glyceraldehyde3-phosphate dehydrogenase (GAPDH), 5'-TTCTAGAGACA GCCGCATCT-3' (forward) and 5'-TGGTAACCAGGTGTC CGATA-3' (reverse). Real-time PCR reaction conditions were: $95^{\circ} \mathrm{C}$ for $30 \mathrm{sec}$; followed by 40 cycles of $95^{\circ} \mathrm{C}$ for $5 \mathrm{sec}$ and $60^{\circ} \mathrm{C}$ for $30 \mathrm{sec}$. Values (mean $\pm \mathrm{SD}$ ) were determined from 4 independent experiments.

Western blot analysis. Tca8113-E2F-1-shRNA cells and Tca8113-NC cells were collected after a 7-day culture, washed twice with cold phosphate-buffered saline (PBS) and lysed in RIPA lysis buffer (Beyotime, Institute of Biotechnology, Haimen, Jiamgsu, China) containing $1 \mathrm{mM}$ phenylmethylsulfonyl fluoride (PMSF). Cell debris was eliminated by centrifugation at $12,000 \mathrm{rpm}$ for $10 \mathrm{~min}$. Protein concentrations were determined using the Bio-Rad protein assay kit (Pierce, Rockford, IL, USA). Proteins (50 $\mu \mathrm{g}$ per lane) were loaded on a $12 \%$ SDS-polyacrylamide gel for electrophoresis, and then transferred onto PVDF membranes (Millipore Co., Bedford, MA, USA) at $300 \mathrm{~mA}$ for $1 \mathrm{~h}$ in a blotting apparatus (Bio-Rad). Membranes were blocked at room temperature for $2 \mathrm{~h}$ with blocking solution $(5 \% \mathrm{w} / \mathrm{v}$ skim milk, $0.01 \mathrm{~mol} / \mathrm{l} \mathrm{PBS}$, $0.1 \%$ Tween-20). The membranes were incubated overnight at $4^{\circ} \mathrm{C}$ with primary polyclonal antibodies against E2F-1 (1:1500; Abcam, Cambridge, MA, USA), cyclin E (1:500; Bioworld, Atlanta, GA, USA), p14 (1:500; Bioworld), p53 (1:500; Bioworld) and monoclonal antibody against $\beta$-actin (1:500; Wuhan Boster Biological Technology Ltd., Wuhan, Hubei, China). Subsequently, the membranes were rinsed with PBST $(0.1 \%$ Tween-20 in $0.01 \mathrm{~mol} / 1 \mathrm{PBS})$, incubated with appropriate horseradish peroxidase-conjugated secondary antibodies at 1:5,000 (Santa Cruz Biotechnology, Inc., Santa Cruz, CA, USA) at room temperature for an additional $1 \mathrm{~h}$, visualized by SuperSignal ${ }^{\circledR}$ West Pico Chemiluminescent Substrate (Thermo, Rockford, IL, USA) and exposed to Kodak X-ray films. The relative intensity of the bands were digitalized and evaluated using Image-Pro Plus 5.0 (Media Cybernetics, Bethesda, MD, USA). $\beta$-actin served as the internal control in these experiments.

Cell proliferation and survival assay. MTT assay was performed to detect the viability and proliferation of the Tca8113 cells. The Tca8113-E2F-1-shRNA and Tca8113-NC cells were seeded into $96-$ well plates at $2 \times 10^{3}$ cells $/ \mathrm{ml}$ and cultured in Dulbecco's modified Eagle's medium (DMEM) with $10 \%$ FBS, penicillin $(100 \mathrm{U} / \mathrm{ml})$, and streptomycin $(100 \mu \mathrm{g} / \mathrm{ml})(1 \%$ Pen/Strep). The cell groups were cultured for 
A
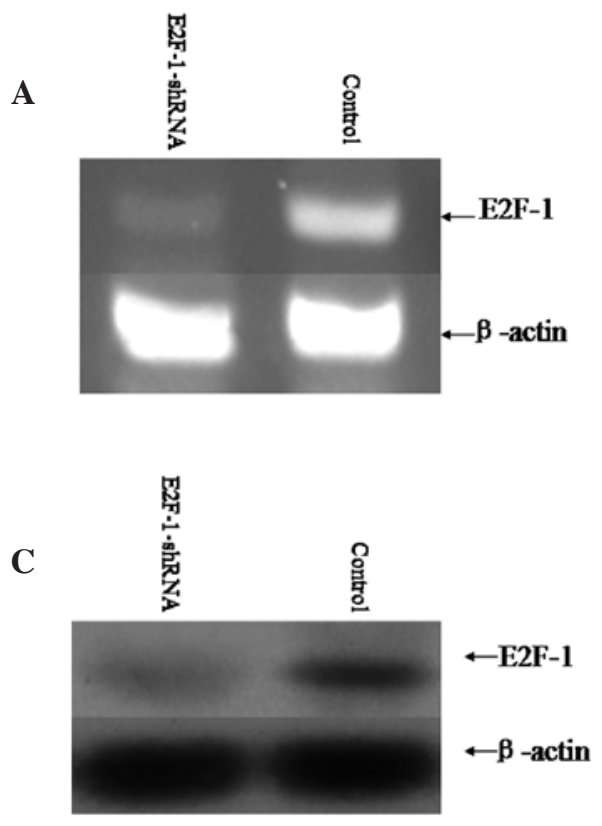

B

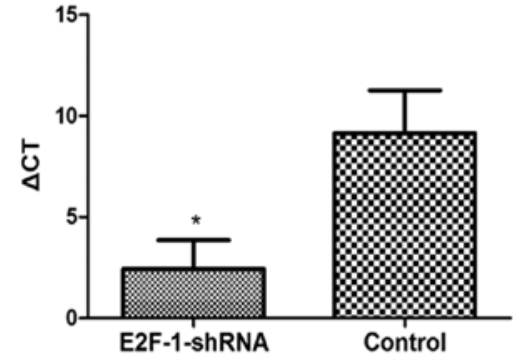

D

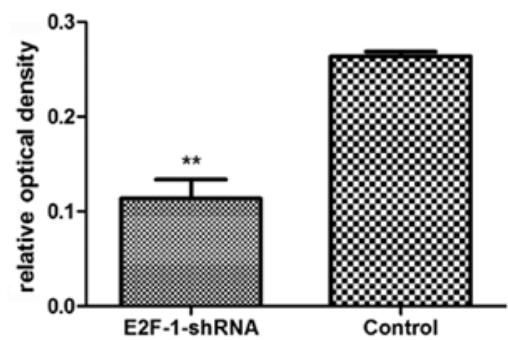

Figure 1. Inhibitory effect of the expression of E2F-1 mRNA and protein. (A) The band of the PCR products was assessed by agarose gel electrophoresis. Lane 1, Tca8113-E2F-1-shRNA cells; lane 2, Tca8113-NC cells. $\beta$-actin was used as a control for each group. (B) The expression of E2F-1 was assessed by quantitative real time-PCR. Gapdh was used as an internal control for each group. Values are the mean \pm SD, $n=3($ ("P $<0.05)$. (C) The expression of E2F-1 protein in Tca8113-E2F-1-shRNA and Tca8113-NC cells was detected by Western blot analysis. $\beta$-actin was used as a control. (D) The relative intensity of positive bands of Tca8113-E2F-1-shRNA and Tca8113-NC cells. Values are the mean \pm SD, $n=3\left({ }^{* *} \mathrm{P}<0.01\right)$.

$1,2,3,4,5,6$ and 7 days. Following each culture time, $20 \mu 1$ MTT $(5 \mathrm{mg} / \mathrm{ml})$ was added to each well, and the cells were incubated at $37^{\circ} \mathrm{C}$ for an additional $4 \mathrm{~h}$. The reaction was then terminated by lysing with $150 \mu$ l DMSO for 5 min. Optical densities were determined on a Versamax microplate reader (Molecular Devices, Sunnyvale, CA, USA) at $490 \mathrm{~nm}$.

Cell cycle analysis by flow cytometry. For cell cycle analysis, Tca8113 cells $\left(1 \times 10^{6}\right)$ were washed twice with ice-cold PBS, treated with trypsin, and then fixed in $70 \%$ cold ethanol at $4^{\circ} \mathrm{C}$ for $30 \mathrm{~min}$. The cell pellet was incubated in a solution containing $50 \mathrm{ng} / \mathrm{ml}$ propidium iodide, $0.2 \mathrm{mg} / \mathrm{ml} \mathrm{RNase}$, and $0.1 \%$ Triton X-100 at room temperature for $30 \mathrm{~min}$, and then analyzed by flow cytometry using a FACscan (BectonDickinson, Mountain View, CA, USA). The data were analyzed with the MultiCycle for Windows (Phoenix Flow Systems, San Diego, CA, USA).

Apoptosis assay by flow cytometry. Apoptotic cells were determined using the Annexin V-FITC Apoptosis Detection kit (Shenzhen Jingmei Biotech Co., Ltd., Shenzhen, Guangdong, China) and an EPICS XLMCL flow cytometer (Becton-Dickinson) according to the manufacturer's instructions. Briefly, $1 \times 10^{6}$ cells were stained with Annexin V/FITC for $30 \mathrm{~min}$ at $4^{\circ} \mathrm{C}$ in the dark and then with propidium iodide for $10 \mathrm{~min}$ before flow cytometric analysis.

Statistical analysis. Data are expressed as the mean \pm standard error of the mean (SEM) analyzed by SPSS 13.0 (SPSS Inc., Chicago, IL, USA). The Student's t-test was used to measure statistical significance between the two treatment groups. Multiple comparisons were performed with one-way analysis of variance (ANOVA). Data were considered significant at $\mathrm{P}<0.05$.

\section{Results}

Inhibitory effect of the expression of E2F-1 mRNA and protein. The sequences of E2F-1-shRNA were transduced to Tca8113 cells by lentiviral vector leading to notable inhibition of E2F-1 mRNA and protein expression. The results of agarose gel electrophoresis, qRT-PCR and Western blotting showed that E2F-1 mRNA and protein in Tca8113-E2F-1-shRNA cells were downregulated significantly, compared with the Tca8113-NC cells $(\mathrm{P}<0.05$; Fig. 1).

Cell growth and proliferation in transfected Tca8113 cells. As shown in Fig. 2, following an initial lag phase, cells began to grow exponentially at day 3 in the Tca8113-NC group and at day 4 in the Tca8113-E2F-1-shRNA group. In the logarithmic phase, population doubling time of Tca8113-NC cells $(33.4 \mathrm{~h})$ was shorter than that of Tca8113-E2F-1-shRNA cells (49.7 h), indicating a quick growth rate of Tca8113-NC cells. The proliferation potential of Tca8113-E2F-1-shRNA and Tca8113-NC cells was further assessed by growth kinetics and flow cytometry in vitro. A representative histogram of flow cytometry revealed that the distribution of Tca8113E2F-1-shRNA cells in the G1 and G2 phases was different from that of the Tca8113-NC cells, but the number of cells in the $\mathrm{S}$ phase showed no differences between the two groups (Fig. 2). The percentage of Tca8113-E2F-1-shRNA cells in G1 phase $(\mathrm{G} 1,36.60 \pm 4.98 \%)$ was markedly lower than that in 
A

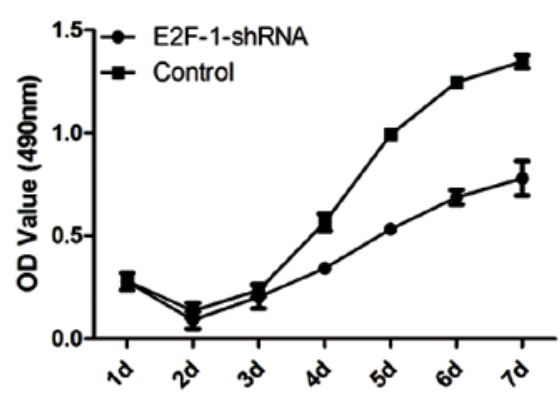

B

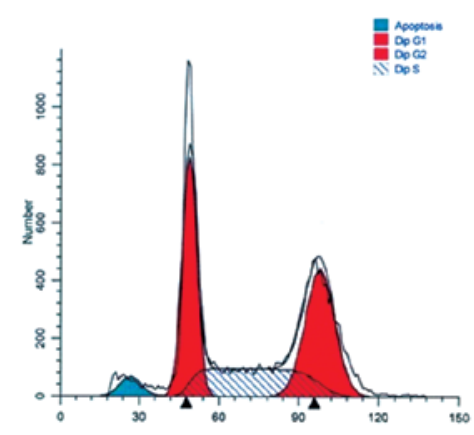

C

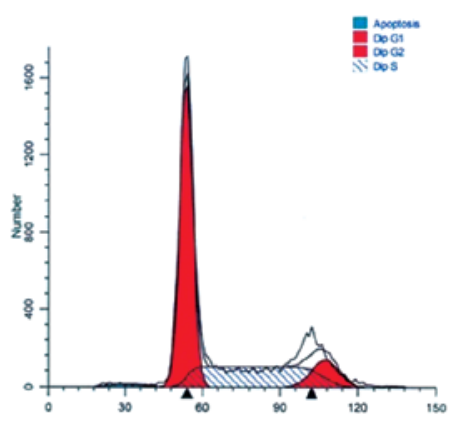

Figure 2. Cell growth and proliferation in transfected Tca8113 cells. (A) Growth curves of Tca8113-E2F-1-shRNA and Tca8113-NC cells. Population doubling time was $33.4 \mathrm{~h}$ in Tca8113-E2F-1-shRNA and $49.7 \mathrm{~h}$ in Tca8113-NC cells. Flow cytometric analyses for (B) Tca8113-E2F-1-shRNA and (C) Tca8113-NC cells.

the Tca8113-NC cells (G1, 58.53 $\pm 0.57 \%, \mathrm{P}<0.05)$, whereas the percentage of Tca8113-E2F-1-shRNA cells in the G2 phase $(\mathrm{G} 2,31.54 \pm 4.88 \%)$ was notably higher than that in Tca8113-NC cells $(\mathrm{G} 2,8.92 \pm 1.23 \%, \mathrm{P}<0.05)$, demonstrating downregulation of the proliferation capacity of Tca8113-E2F-1-shRNA cells.

Apoptosis in transfected Tca8113 cells. In addition to the function of E2F-1 to induce proliferation, E2F-1 also leads to apoptosis through multiple pathways. To study the alteration of apoptosis in Tca8113 cells after downregulation of E2F-1, cells were stained with Annexin V-FITC and PI, and then subsequently analyzed by flow cytometry. The cells undergoing early apoptosis are shown in the lower right quadrant (Annexin $\mathrm{V}^{+} / \mathrm{PI}^{-}$), and the cell undergoing late apoptosis or necrosis are shown in the upper right quadrant (Annexin $\mathrm{V}^{+}$ $\mathrm{PI}^{+}$). As shown in Fig. 3, the percentage of Tca8113-E2F-1shRNA cells with Annexin $\mathrm{V}^{+} / \mathrm{PI}^{-}$staining was significantly higher than that of the Tca8113-NC cells $(\mathrm{P}<0.05)$. This finding indicates that inhibition of $\mathrm{E} 2 \mathrm{~F}-1$ was able to induce apoptosis in Tca8113 cells.

Alteration of the regulation of cyclin E, p14 and p53 in Tca8113 cells upon downregulation of E2F-1. Real-time PCR findings were consistent with the results of Western blot analysis and revealed that the gene expression of cyclin E, p14 and p53 was significantly downregulated in Tca8113-E2F-1-shRNA cells (Fig. 4A, P<0.05), while Rb showed no significant differences. By contrast, Tca8113-NC cells, and the protein expression of cyclin E, p14 and p53 were decreased in the Tca8113-E2F-1-shRNA group (Fig. 4B and $\mathrm{C}, \mathrm{P}<0.05$ ), accompanied by no differences of pRb between Tca8113-E2F-1-shRNA and Tca8113-NC cells.
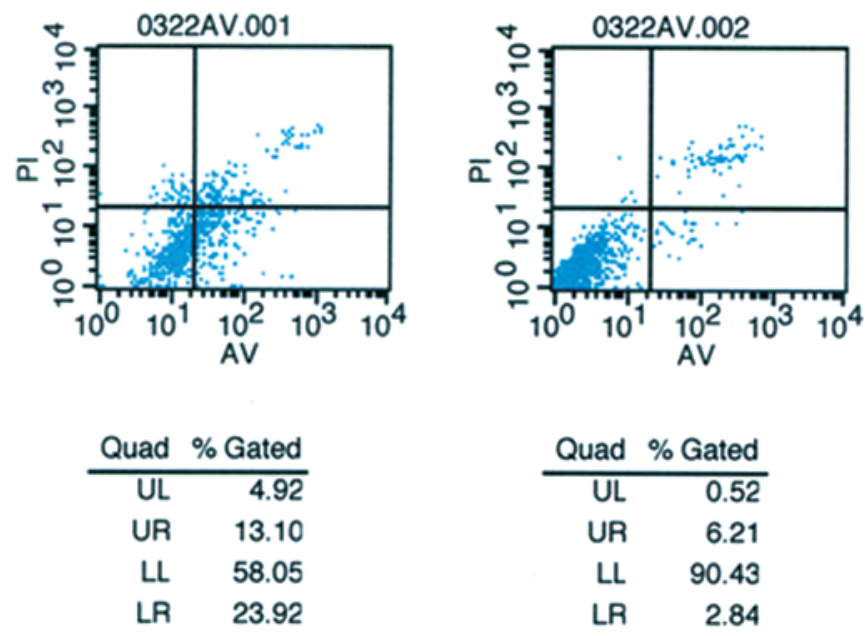

Figure 3. Apoptosis in the transfected Tca8113 cells. The percentage of Tca8113-E2F-1-shRNA cells with Annexin $\mathrm{V}^{+} / \mathrm{PI}^{-}$staining was significantly higher than that of Tca8113-NC cells. Values are the mean $\pm S D, n=3(P<0.05)$.

\section{Discussion}

Numerous findings suggest that E2F-1 has a tissue-specific effect that enables it to induce proliferation as an oncogene, while also stimulating apoptosis as a tumor-suppressor gene in different cancers and cell lines. Enforced expression of E2F-1 in vitro has been shown to cause not only cell cycle progression but also apoptosis in a number of cell types $(16,17)$. In this study, downregulation of E2F-1 in Tca8113 cells by a transfected lentivirus led to significant inhibition of cell growth and 


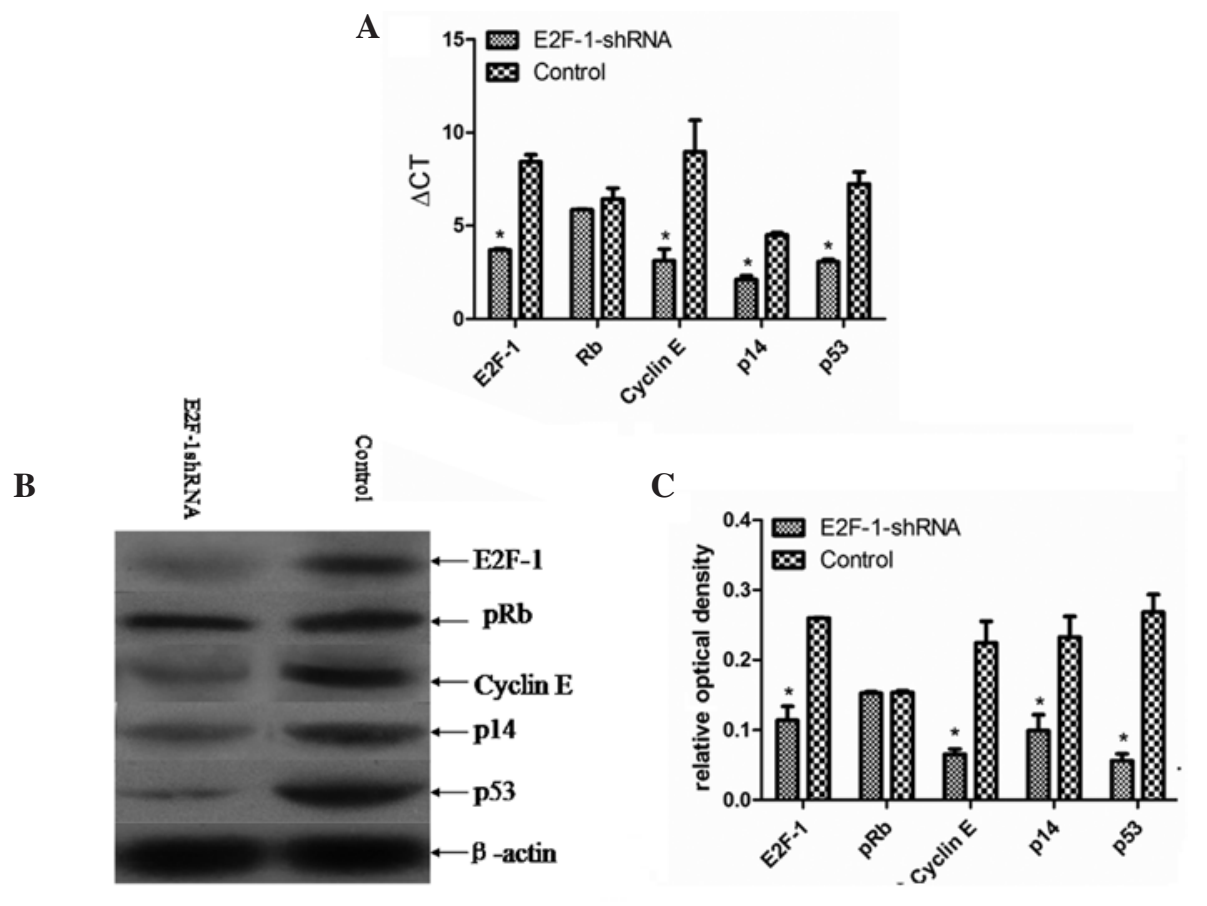

Figure 4. Alteration of the regulation of cyclin E, p14 and p53 in Tca8113 cells upon downregulation of E2F-1. (A) Gene expression of E2F-1, pRb, cyclin E, p14 and p53 in Tca8113-E2F-1-shRNA and Tca8113-NC cell samples. GAPDH was used as an internal control for each group. Values are the mean \pm SD, $\mathrm{n}=3$ ("P<0.05). (B) Protein expression of E2F-1, pRb, cyclin E, p14 and p53 in Tca8113-E2F-1-shRNA and Tca8113-NC cells. $\beta$-actin was used as the control. (C) The relative intensity of positive bands of Tca8113-E2F-1-shRNA and Tca8113-NC cells in B. Values are the mean $\pm \mathrm{SD}, \mathrm{n}=3$ ("P<0.05).

caused cell cycle arrest in the G2/M phase. Moreover, we also detected a higher level of apoptosis than in control Tca8113 cells. To examine the role of E2F-1 in pathways controlling cell proliferation and apoptosis, we investigated its negative regulator $(\mathrm{pRb})$ and target genes for proliferation (cyclin $\mathrm{E})$ and apoptosis (p14ARF, p53). Notably, both mRNA and protein expression levels of cyclin E, p14ARF and p53 were found to be significantly decreased, while the expression of $\mathrm{pRb}$ revealed no marked alteration with the knockdown of expression of E2F-1 in Tca8113-E2F-1-shRNA cells. This study showed that E2F-1 not only regulates downstream target gene cyclin E but also induces the p14/MDM2/p53-dependent pathway; E2F-1 stimulates cell growth in OSCC cell line Tca8113.

The cell cycle is controlled by numerous mechanisms, including the regulation of cyclin-dependent kinases (CDK) by cyclins, CDK inhibitors and phosphorylation events (18). Mechanistically, it is known that E2F-1 activates a variety of genes required for $\mathrm{S}$ phase entry, DNA replication and synthesis $(19,20)$. Consistent with this, overexpression of E2F can also bypass G1 phase arrest imposed by various stimuli. Transcriptional activity of E2F-1 has been found to be activated in cooperation with deregulation of the $\mathrm{pRb} / \mathrm{E} 2 \mathrm{~F}-1$ complex in almost all human cancers, due to the mutation or deletion of $\mathrm{pRb}$, or upstream regulators in this pathway, such as p16 silencing, amplification of cyclin D1 or cdk4 (21).

When quiescent cells are stimulated by growth factors or mitogenic signals, the D-type cyclins are the first to be activated. D-type cyclins associate with CDK4 or CDK6 and function at the early G1 phase. CDK4 associates with the D-type cyclins to mediate the phosphorylation of the retinoblastoma $(\mathrm{Rb})$ family protein $(22)$. This event inactivates the ability of the $\mathrm{pRb} / \mathrm{E} 2 \mathrm{~F}$ complex to release E2Fs and then initi- ates transcription of genes required for S phase entry. Many of the upregulated genes encode proteins involved in DNA replication and cell-cycle progression, such as DNA polymerases, minichromosome maintenance complex components (MCMs), cdc6 and cyclin E (23). In this study, E2F-1 downregulation via RNAi did not change the status of $\mathrm{pRb}$ in the Tca8113-E2F1-shRNA cells, thus the inactivated $\mathrm{pRb} / \mathrm{E} 2 \mathrm{~F}-1$ complex may have little effect on the progression of the cell cycle. Cell cycle analysis demonstrated that the ratio of Tca8113-E2F-1-shRNA cells at the G1 phase was lower than that in the Tca8113-NC cells, while the proportion of cells in the $\mathrm{S}$ phase showed no significant differences. It may be concluded that knockdown of E2F-1 downregulates cyclin E to alter the activity of the cyclin E-CDK 2 complex but not the state of $\mathrm{S}$ phase in Tca8113-E2F1-shRNA cells. In the E2F family, E2F1, E2F2 and E2F3a, which interact only with $\mathrm{pRB}$, constitute a subfamily and are often referred to as the 'activator E2Fs', due to the fact that they appear to function mainly in activating gene expression. In line with the regulation of many proliferation-related genes by E2F, overexpression of E2F1, E2F2 or E2F3a induces quiescent immortalized cells to enter the S-phase (24). Different activator E2Fs appear to have partially overlapping, but distinct, roles in the regulation of cell proliferation. Both E2F1 and E2F3 are required for cell-cycle entry, but only E2F3 is required for continued cell proliferation (25). Combined loss of E2F1, E2F2 and E2F3 completely abolishes the ability of cells to progress through the cell cycle and proliferate (26). Therefore, activator E2Fs are associated with roles in G1-S transition and only downregulation of E2F-1 may have some effect on the alteration of S phase.

Components of the checkpoint mechanism include sensors, mediators, transducers and effectors, which act together in 
different phases of the cell cycle (27). The first checkpoint, found at the G1/S transition, is compromised in many malignant cells, due to mutations in various tumor-suppressor genes, including retinoblastoma protein $(\mathrm{Rb})$ and $\mathrm{p} 53$. Cells deficient in the G1 checkpoint are dependent on the S and G2 checkpoints for DNA repair. p53-dependent arrest of cells in the G1 phase of the cell cycle is an important component of the cellular response to stress. Evidence also suggests that p53 controls entry into mitosis when cells enter G2 with damaged DNA or when they are arrested in the $S$ phase, due to depletion of the substrates required for DNA synthesis. Part of the mechanism by which p53 blocks cells at the $\mathrm{G} 2$ checkpoint involves inhibition of $\mathrm{Cdc} 2$, the cyclin-dependent kinase required to enter mitosis (28). In the present study, accompanied by E2F-1 knockdown, expression of p53 decreased in Tca8113-E2F-1shRNA cells, the cell growth was reduced significantly and the cell cycle was arrested in G2/M. While it is possible that p53 also contributed to the initial arrest, it is clear that additional pathways can cause arrest when p53 is missing.

Indeed, mechanisms of G2 arrest are controlled on multiple levels and are related to a variety of effector molecules. Checkpoint kinase-1 and checkpoint kinase-2 are the checkpoint transducer kinases that function downstream in the DNA-damage checkpoint signalling pathway. Chk2, expressed throughout the cell cycle, is activated in the presence of DNA damage (29). By contrast, Chk1, preferentially expressed during $\mathrm{S}$ and $\mathrm{G} 2$, has constitutive activity that is amplified in the presence of DNA damage (30). Chk1 and Chk2 can be phosphorylated by ATR and ATM respectively, and significant crosstalk exists between the ATM/Chk2 and ATR/Chk1 pathways (31). In addition, another transducer kinase called MAPKAP kinase-2 (MK2) is directly involved in phosphorylating effectors CDC25B and C, and in maintaining G1, S, and $\mathrm{G} 2$ checkpoints (32) and its response is essential for the survival of p53-deficient cells (33).

Apart from its ability to induce proliferation, E2F-1 was also found to be capable of inducing apoptosis, as was shown by determining that both p14ARF and p53 were downregulated upon E2F-1 mRNA interference. Several studies have identified p14ARF as a key molecule that links Rb/E2F1 and the p14ARF-MDM-p53 apoptosis pathway and this has stimulated research involving the process of E2F-1-regulated apoptosis $(34,35)$. However, analysis of the percentage of apoptotic cells by flow cytometry showed that the percentage of Tca8113-E2F-1-shRNA cells undergoing apoptosis was markedly higher than that in Tca8113-NC cells. It follows that the apoptosis of Tca8113-E2F-1-shRNA cells involves other mechanisms. We believe that other apoptotic mechanisms exist in Tca8113-E2F-1-shRNA cells that exhibit lower expression of E2F-1.

E2F-1-mediated cell death has been studied in depth, however, an apoptotic role for E2F-1 in cancer has yet to be fully defined and loss of E2F-1, for example, in Myc-mediated lymphomagenesis, does not necessarily lead to apoptosis resistance (36). In this situation, the inactivation of E2F-1 leads instead to the inhibition of the enhanced cell cycle progression caused by c-Myc, indicating that targeting of E2F-1 itself may prove beneficial (4). The pathways involving E2F-1 and apoptosis are multiple and interactive. Downregulation of E2F-1 may affect the interaction among molecules in the network of the cell cycle and may indirectly induce apoptosis by other mechanisms.

In conclusion, it is evident from this study that E2F-1 may be involved in pathways of proliferation and apoptosis; however, downregulation of E2F-1 can reduce proliferation of Tca8113 cells more significantly in vitro. These findings suggest that the role of E2F-1 in OSCC requires further clarification and the multiple mechanisms involved in gene therapies targeting E2F-1 still need to be fully elucidated.

\section{Acknowledgements}

This work was supported by grants from the Medical Development Foundation of the Health Department of Jiangsu Province (H200811) and the Natural Science Foundation of Jiangsu Higher Education Institutions (08KJB320008).

\section{References}

1. Parkin DM, Bray F, Ferlay J and Pisani P: Global cancer statistics, 2002. CA Cancer J Clin 55: 74-108, 2005.

2. Carpenter JM, Syms MJ and Sniezek JC: Oral carcinoma associated with betel nut chewing in the Pacific: an impending crisis? Pac Health Dialog 12: 158-162, 2005.

3. Hanahan D and Weinberg RA: The hallmarks of cancer. Cell 100: 57-70, 2000.

4. Bell LA and Ryan KM: Life and death decisions by E2F-1. Cell Death Differ 11: 137-142, 2004.

5. Kovesdi I, Reichel R and Nevins JR: Identification of a cellular transcription factor involved in E1A trans-activation. Cell 45: 219-228, 1986.

6. Johnson DG: Regulation of E2F-1 gene expression by $130(\mathrm{Rb} 2)$ and D-type cyclin kinase activity. Oncogene 11: 1685-1692, 1995.

7. Lundberg AS and Weinberg RA: Functional inactivation of the retinoblastoma protein requires sequential modification by at least two distinct cyclin-cdk complexes. Mol Cell Biol 18: 753-761, 1998.

8. Johnson DG, Cress WD, Jakoi L and Nevins JR: Oncogenic capacity of the E2F1 gene. Proc Natl Acad Sci USA 91: 12823-2827, 1994.

9. DeGregori J,Kowalik T and Nevins JR: Cellular targets for activation by the E2F1 transcription factor include DNA synthesis- and G1/S-regulatory genes. Mol Cell Biol 15: 4215-4224, 1995.

10. Ohtani K, DeGregori J and Nevins JR: Regulation of the cyclin E gene by transcription factor E2F1. Proc Natl Acad Sci USA 92: 12146-12150, 1995.

11. Lukas J, Petersen BO, Holm K, Bartek J and Helin K: Deregulated expression of E2F family members induces S-phase entry and overcomes p16INK4A-mediated growth suppression. Mol Cell Biol 16: 1047-1057, 1996.

12. Vorburger SA, Pataer A, Yoshida K, et al: Role for the doublestranded RNA activated protein kinase PKR in E2F-1-induced apoptosis. Oncogene 21: 6278-6288, 2002.

13. Kwong RA, Nguyen TV, Bova RJ, et al: Overexpression of E2F-1 is associated with increased disease-free survival in squamous cell carcinoma of the anterior tongue. Clin Cancer Res 9: 3705-3711, 2003.

14. Soni S, Kaur J, Kumar A, et al: Alterations of rb pathway components are frequent events in patients with oral epithelial dysplasia and predict clinical outcome in patients with squamous cell carcinoma. Oncology 68: 314-325, 2005.

15. Du Y, Zhang S, Wang Z, et al: Induction of apoptosis and cell cycle arrest by NS398 in oral squamous cell carcinoma cells via downregulation of E2 promoter-binding factor-1. Oncol Rep 20: 605-611, 2008.

16. Shan B and Lee WH: Deregulated expression of E2F-1 induces S-phase entry and leads to apoptosis. Mol Cell Biol 14: 8166-8173, 1994.

17. $\mathrm{Wu} \mathrm{X}$ and Levine AJ: p53 and E2F-1 cooperate to mediate apoptosis. Proc Natl Acad Sci USA 91: 3602-3606, 1994.

18. Vermeulen K, Van Bockstaele DR and Berneman ZN: The cell cycle: a review of regulation, deregulation and therapeutic targets in cancer. Cell Prolif 36: 131-149, 2003. 
19. Cam $\mathrm{H}$ and Dynlacht BD: Emerging roles for E2F: beyond the G1/S transition and DNA replication. Cancer Cell 3: 311-316, 2003.

20. Stevaux O and Dyson NJ: A revised picture of the E2F transcriptional network and RB function. Curr Opin Cell Biol 14: 684-691, 2002

21. Sherr CJ and McCormick F: The RB and p53 pathways in cancer. Cancer Cell 2: 103-112, 2002.

22. Sherr CJ: D-type cyclins. Trends Biochem Sci 20: 187-190, 1995.

23. Polager S and Ginsberg D: E2F - at the crossroads of life and death. Trends Cell Biol 18: 528-535, 2008.

24. DeGregori J and Johnson DG: Distinct and overlapping roles for E2F family members in transcription, proliferation and apoptosis. Curr Mol Med 6: 739-748, 2006.

25. Kong LJ, Chang JT, Bild AH and Nevins JR: Compensation and specificity of function within the E2F family. Oncogene 26: 321-327, 2007.

26. Wu L, Timmers C, Maiti B, et al: The E2F1-3 transcription factors are essential for cellular proliferation. Nature 414: 457-462, 2001.

27. Sancar A, Lindsey-Boltz LA, Unsal-Kacmaz K and Linn S: Molecular mechanisms of mammalian DNA repair and the DNA damage checkpoints. Annu Rev Biochem 73: 39-85, 2004.

28. Taylor WR, DePrimo SE, Agarwal A, et al: Mechanisms of G2 arrest in response to overexpression of p53. Mol Biol Cell 10: 3607-3622, 1999.

29. Lukas C, Bartkova J, Latella L, et al: DNA damage-activated kinase Chk 2 is independent of proliferation or differentiation yet correlates with tissue biology. Cancer Res 61: 4990-4993, 2001.
30. Zhao H, Watkins JL and Piwnica-Worms H: Disruption of the checkpoint kinase 1 /cell division cycle $25 \mathrm{~A}$ pathway abrogates ionizing radiation-induced $\mathrm{S}$ and $\mathrm{G} 2$ checkpoints. Proc Natl Acad Sci USA 99: 14795-14800, 2002.

31. Gatei M, Sloper K, Sorensen C, et al: Ataxia-telangiectasiamutated (ATM) and NBS1-dependent phosphorylation of Chk1 on Ser-317 in response to ionizing radiation. J Biol Chem 278: 14806-14811, 2003.

32. Manke IA, Nguyen A, Lim D, Stewart MQ, Elia AE and Yaffe MB: MAPKAP kinase-2 is a cell cycle checkpoint kinase that regulates the $\mathrm{G} 2 / \mathrm{M}$ transition and $\mathrm{S}$ phase progression in response to UV irradiation. Mol Cell 17: 37-48, 2005.

33. Reinhardt HC, Aslanian AS, Lees JA and Yaffe MB: p53-deficient cells rely on ATM- and ATR-mediated checkpoint signaling through the p38MAPK/MK2 pathway for survival after DNA damage. Cancer Cell 11: 175-189, 2007.

34. Almasan A, Yin Y, Kelly RE, et al: Deficiency of retinoblastoma protein leads to inappropriate S-phase entry, activation of E2F-responsive genes, and apoptosis. Proc Natl Acad Sci USA 92: 5436-5440, 1995.

35. Bates S, Phillips AC, Clark PA, et al: p14ARF links the tumour suppressors RB and p53. Nature 395: 124-125, 1998.

36. Baudino TA, Maclean KH, Brennan J, et al: Myc-mediated proliferation and lymphomagenesis, but not apoptosis, are compromised by E2f1 loss. Mol Cell 11: 905-914, 2003. 